\title{
Our suffering and the suffering of our time
}

\author{
John D. Lantos ${ }^{1}$
}

Published online: 7 December 2020

(C) Springer Nature B.V. 2020

When Bird, the twenty-seven-year-old first-time father in Kenzaburo Oe's novel $A$ Personal Matter, learns that his newborn son has a brain anomaly, his first reaction is to wonder whether the baby is suffering. The doctor says, "That depends on what you mean by suffering. I mean, the baby can't see or hear or smell, right? And I bet the nerves that signal pain aren't functioning, either. ... In your opinion, does a vegetable suffer?" [1, p. 23]. In response, "Bird meekly shook his head: as if to say the problem exceeded his flushed brain's capacity for judgment" [1, p. 24].

The essays in this issue attempt to answer Bird's question.

When Bird first sees his baby, he recoils in disgust: "An ugly baby with a pinched, tiny, red face covered with wrinkles and blotchy with fat. ... Beneath the bandage, the skull was buried under a mound of bloody cotton; but there was no hiding the presence there of something large and abnormal" [1, p. 24].

Then Bird's mind makes a surprising connection.

He thinks, "My son has bandages on his head and so did Apollinaire when he was wounded on the field of battle. On a dark and lonely battlefield I have never seen, my son was wounded like Apollinaire and now he is screaming soundlessly. ... I'll have to bury him like a soldier who died at war" [1, pp. 24-25].

By imagining a glorious future for his brain-damaged son-Apollinaire was an innovative poet-Bird begins to both recognize his own internal conflicts and move toward their psychological resolution. On the one hand, he wants to save his baby. On the other, he has accepted his baby's death and his own complicity in allowing that death to occur. Oe writes, "Head in bandages, like Apollinaire: the image simplified his feelings instantly and directed them. He could feel himself turning into a sentimental jelly, yet he felt himself being sanctioned and justified" [1, p. 24].

The simultaneous feelings of wanting to save his baby and wanting to let his baby die are wildly contradictory. Of course they are wildly contradictory. His flushed brain has lost the capacity for judgment. He is a bowl of sentimental jelly. Yet a decision has to be made.

John D. Lantos

jlantos@cmh.edu

1 Children's Mercy Hospital, Kansas City, MO 64108, USA 
Oe's book, and the essays contained in this special issue, are meditations on the tragic choices faced by parents of critically ill newborns and whether those choices are sanctioned and justified.

Baby Esther's doctors and parents faced a tough dilemma that was nearly identical to Bird's (see [2]). Which choice was preferable: letting her die when an operation could prolong her life or doing the operation and thus prolonging her suffering?

The first challenge in resolving such dilemmas is to categorize them. Most doctors and bioethicists see them as philosophical or legal or even neurological dilemmas. For most parents, though, the dilemmas are fundamentally spiritual. For many, the question is not (or not primarily) about whether their baby is suffering or about what is best for their baby; rather, it is about what God wants of them-or, for those who do not frame such questions in terms of God, what it means to be a good parent.

A number of pediatricians, bioethicists, philosophers, and theologians have struggled to understand the complexity of these situations and decisions. Margaret Mohrmann, a pediatric intensive care doctor who is also a theologian, has written sensitively and insightfully about situations in which parents desire to keep their sick children alive, even if their children are suffering, because they believe that just in being alive their children can still "serve God." She also acknowledges that theological beliefs can lead to very different conclusions. Other parents find peace in the belief that if their children die, their death is good for them, since only in death can they move on to an "eternal life with God" [3, p. 148]. These seemingly opposed responses may simply reflect the sort of thinking that comes from flushed brains and jelly hearts. Or it may be that the situations themselves are of a sort that allows even the most rigorous reasoning to give rise to very different conclusions.

Mohrmann believes that the fundamental question at the center of such dilemmas - the question of whether a baby is suffering - is absolutely unanswerable. The experiences of a baby are knowable only empathically, never directly. A baby's feelings and interests cannot be disentangled from the perceptions, emotions, and interests of the baby's doctors, nurses, and parents. As she says, "The inseparability of interests is apparent when we consider that the futures of children and their parents are, in many key senses, interdependent. We say that children are our future, but we are just as surely theirs, a truth which complicates every child's right to an open future" [3, p. 147].

Georgina Campelia and colleagues agree. They suggest that what matters in such cases is the nature of the relationships in which such a child is ensconced. They write, "Looking to Esther alone and seeking objective information about her suffering ... may fail to consider the particular, dependent, loving, and emotional relations that are partly constitutive of Esther, her suffering, and the suffering that surrounds her" [4]. Esther, they submit, can be best understood not as an individual but as a participant in many complex relationships. Those relationships give her life meaning. The authors take it as given that Esther's underlying disease cannot be cured and even that her pain cannot be adequately controlled. In view of those facts, her doctors see "a future of surgeries, ventilator dependence, and dressing and line changes that they would not wish for themselves or their own family members" [4]. Her parents see something completely different. They 
want to do everything they can to bring her home so as to allow their relationships with her to continue to grow and develop.

Tyler Tate also incorporates two wildly different views of Esther and the meaning of her potential suffering. A baby's suffering, he offers, can be viewed as a "scandal" or as a "mirage" [5]. It would be a scandal to let Esther suffer if there is no hope of survival; the only humane response, on this view, would be to let (or help) her die. Her suffering is a mirage if, as the doctor suggests about Bird's son, she does not have the neurological capacity to suffer.

To take a stand between these two views, Tate first observes that we all suffer in one way or another. We suffer when relationships go bad. We suffer when we are conflicted about our life goals and must make decisions. We suffer when we are hungry or lonely. He writes, "feeling bad is a daily, ever-fluctuating part of all children's lives" [5]. Such suffering must be judged, Tate suggests, based on a judgment about whether the suffering is "requisite and critical for a newborn to grow into an infant, an infant into a toddler, a toddler into a child, a child into an adolescent, and an adolescent into a functioning and well-adjusted adult" [5]. In other words, "a purely experiential account of suffering will not suffice" [5]. Instead, one must know whether the suffering leads somewhere and thus has a purpose.

Dominic Wilkinson and Amir Zayegh delve into similar speculations by highlighting the ways in which the suffering experienced by cognitively impaired infants is judged in light of their prognosis for long-term survival. These authors suggest that if a baby will not survive infancy, then the developmental aspects of suffering - the purpose of it, as outlined by Tate-lose meaning. A life that is destined to be very short and that is filled with painful medical procedures lacks the "subjective and objective components of well-being" that would compel continuation of all available life-sustaining treatments [6]. They write, "While residual suffering is often tolerated in patients who have a chance of recovery (and therefore a life of positive net well-being), there is less justification for tolerating suffering in patients with severe life-limiting conditions where there is no major uncertainty regarding future outcome" [6].

These analyses can help parents and clinicians who are on the spot and must make decisions. They give reasons that may bolster choices and suggest ways to think about what we owe to babies, what we owe to ourselves, and what we owe to God. They explicate the implications of rationales used to make choices and show how any ethical judgment about those choices depends on subtle perceptual nuances that can be perceived only in real time by those who are actually involved.

Decisions must be made for babies like Esther. The ventilator will be either continued or stopped. The diagnostic evaluation for sepsis will be either initiated or foregone. The abdominal surgery will be either performed or eschewed. Doctors, nurses, and parents together have to choose. The toughest decisions will involve babies whose lives are diminished in both their capacity for experience and their short length. Each decision, then, becomes a profound enactment of a tragic drama on a very small stage. Each drama both reflects and shapes the values of the larger community in which it unfolds, and that larger community in turn both embodies and constitutes the milieu in which future consciences are formed. 
Indeed, in cases like Esther's, at least two interlocking dramas are playing out at once. One is the techno-medical drama in which the vast armamentarium of lifesaving interventions that we call critical care medicine is pitted against the infinite variety of things-gone-wrong that we call disease. The other is the religious or spiritual drama in which doctors, nurses, and parents all struggle to figure out how they should act in order to be at peace with their own consciences.

These interlocking dramas are quite personal. Yet they have societal implications. Societies make laws and policies that determine the boundaries of the domains within which personal decisions are permissible. In some societies, for example, active euthanasia is legal. In others, it is illegal for a doctor to withdraw life-sustaining treatment. The collective subsidization of intensive care for babies like Esther is available in some societies and not in others. Society establishes the ground rules that determine which individual choices are made.

Detailed case reports illustrate how doctors, nurses, and parents work together and come to decisions [7]. In some cases, parents eventually elect to withdraw life support. In others, doctors agree to continue such treatment. In some cases, parents repeatedly express "their appreciation of the physicians' efforts on behalf of their children" and accept "their child's death calmly" [8]. In others, parents attempt to compel continued treatment in the courts, which sometimes order treatment to be continued and sometimes permit discontinuation of life support. Each of these cases adds to our compendium of knowledge and vicarious experiences and enriches our understanding of what is at stake.

In some ways, the question of whether Esther is or is not, in fact, suffering is both simpler and, oddly, less crucial than the aforementioned analyses suggest. One could instead simply assume that she is suffering because all patients in an intensive care unit suffer. They suffer physically, emotionally, and existentially. The crucial question, then, is whether the suffering can be "sanctioned and justified." Is there a purpose to the suffering and to an individual's role in both authorizing and inflicting it? Must there be something on the other side of the scale that offsets the dead weight of inevitable suffering? Tate posits that the counterweight to suffering is flourishing. If there is a possibility that continuing treatment will lead to flourishing, then the suffering caused by that treatment can be justified.

Kenzaburo Oe's lifework helps to elucidate how such decisions shape each of the people involved and also, ultimately, shape the world in which we live. Such decisions, he suggests, are fundamentally and irreducibly personal. Bird is deeply alone as he struggles with his tortured soul, trying to determine what sort of father and person he wants to be. He worries that his struggle to figure out what choice to make "won't result in so much as a fragment of significance for anybody else" [1, p. 120]. But Oe, Bird's real-world alter ego, asserts the opposite truth. By writing his Nobelwinning novel, he contends that his experience has universal significance that goes far beyond his personal matter.

Oe wrote A Personal Matter because, in his own life, he had faced a decision similar to that faced by Esther's parents and doctors. He had to decide whether to authorize a risky surgery for his son, a surgery that may or may not turn out to be beneficial. The decision that he made (and that I will not reveal in this paper-go read the book!) altered his life. The novel tries to make sense of what he did and 
what was at stake. Oe is doing what great healers do and what each of us who cares for suffering strangers tries to do: We try to help people make sense of their suffering and make choices that might reflect the sense that they make. In his 1994 Nobel Prize acceptance speech, Oe described his task as a novelist as enabling "both those who express themselves with words and their readers to recover from their own sufferings and the sufferings of their time, and to cure their souls of the wounds" [9]. This is also the task of those whose efforts to heal take place not through literature but through medicine and the healing arts.

\section{References}

1. Oe, Kenzaburo. 1968. A personal matter. Trans. John Nathan. New York: Grove Press.

2. Tate, Tyler. 2020. Philosophical investigations into the essence of pediatric suffering. Theoretical Medicine and Bioethics 41. https://doi.org/10.1007/s11017-020-09531-y.

3. Mohrmann, Margaret E. 2006. Whose interests are they, anyway? Journal of Religious Ethics 34: 141-150.

4. Campelia, Georgina D., Jennifer C. Kett, and Aaron Wightman. 2020. Relational suffering and the moral authority of love and care. Theoretical Medicine and Bioethics 41. https://doi.org/10.1007/ s11017-020-09530-z.

5. Tate, Tyler. 2020. What we talk about when we talk about pediatric suffering. Theoretical Medicine and Bioethics 41. https://doi.org/10.1007/s11017-020-09535-8.

6. Wilkinson, Dominic, and Amir Zayegh. 2020. Valuing life and evaluating suffering in infants with life-limiting illness. Theoretical Medicine and Bioethics 41. https://doi.org/10.1007/s11017-02009532-x.

7. Feltman, Dalia, Theophil Stokes, Jennifer Kett, and John D. Lantos. 2014. Is treatment futile for an extremely premature infant with giant omphalocele? Pediatrics 133: 123-128.

8. Okhuysen-Cawley, Regina, Mona L. McPherson, and Larry S. Jefferson. 2007. Institutional policies on determination of medically inappropriate interventions: Use in five pediatric patients. Pediatric Critical Care Medicine 8: 225-230.

9. Oe, Kenzaburo. 1995. Japan, the ambiguous and myself. In Les prix nobel: The nobel prizes 1994, ed. Tore Frängsmyr, 207-220. Stockholm: Almquist and Wiksell. https://www.nobelprize.org/prize s/literature/1994/oe/lecture.

Publisher's Note Springer Nature remains neutral with regard to jurisdictional claims in published maps and institutional affiliations. 